\title{
Language Personality in the Conditions of Cross-Cultural Communication: Case-Study Experience
}

\author{
Nitza Davidovitch ${ }^{1} \&$ Kateryna Khyzhniak ${ }^{2}$ \\ ${ }^{1}$ Center's Unit of Academic Assessment and Development, Ariel University, Ariel, Israel \\ ${ }^{2}$ Department of Intercultural Communication and Foreign Languages, National Technical University "Kharkiv \\ Polytechnic Institute", Kharkiv, Ukraine \\ Correspondence: Kateryna Khyzhniak, vul. Otakara Iarosha 11a, kv. 63, Kharkiv, Ukraine. Tel: 38-097-549-5041. \\ E-mail: khyzhniakk@gmail.com
}

Received: May 2, 2017

doi: $10.5539 /$ ies.v $11 \mathrm{n} 2 \mathrm{p} 13$
Accepted: June 16, 2017 Online Published: January 26, 2018

URL: https://doi.org/10.5539/ies.v11n2p13

\begin{abstract}
The article is devoted to the problem of identification of a language personality's traits under conditions of cross-cultural communication. It is shown that effective cross-cultural communication is revised under globalization and increasingly intensive social interactions. The results of the authors' research prove that it is possible to develop a new perspective on the heuristic possibilities of the concept of language personality to ensure the effectiveness of cross-cultural communications.

This applies above all to the understanding of culture, cultural codes, verbal, non-verbal communication and preverbal, development of value measurement and understanding, and behavior adoption patterns. We propose to identify a language personality as a nationally specific communicant type that has a culturally caused worldview and value system and is capable of cross-cultural transformation. We identified transitions from a "mono" language personality to a "multi" language personality. We offer communicative training as a way of resolving cultural gaps in communication.

We insist that only a new type of a language personality can effectively integrate and communicate while taking into account cultural peculiarities. Language personality currently acquires multicultural traits resulting from two main types of mobility: virtual and physical. Empirical research shows that two types of mobility are widespread, with typical high demands for the study of an international communication language (English) and local culture (Hebrew).
\end{abstract}

Keywords: language personality, cross-cultural communication, cross-cultural competence, communicative training

\section{Introduction}

\subsection{Language and Communication: Traits of a New Personality}

Language is a communicative process in its pure form in every society expressed by means of communication, it helps communication, and it is the most important, the most explicit, and the most formal and socially recognized form of communicative behavior. Language preserves cultural values - in its vocabulary, grammar, idioms, proverbs, sayings, folklore, and in the fictional and the scientific literature, in both written and spoken language. According to Hirsch (1988) modern personality should have the ability to understand and participate fluently in a given culture, so called "cultural literacy". Hall (1977) points that to interact in intercultural communication each personality should mind the peculiarities of high and low contextual cultures. According to Veltkamp, Recio, Jacobs, and Conrad (2013), language pays the biggest role in modulating the personality.

As a result, language personality is emerging, due to its socio-cultural environment. Vorozhbitova and Issina (2014) argue that from the standpoint of linguistic and rhetorical paradigm a hierarchically dominant monoposition of category "linguistic personality" is substantiated, while such concepts as "speech personality", "communicative personality," etc. represent only certain aspects of linguistic and rhetorical functioning. Today, in terms of activation and massification of social mobility, the world is transformed into a multicultural space everywhere. Personality is involved in the different types of mobility (physical, virtual, etc.) and faces numerous socio-cultural challenges that cause different changes in types and forms of communication. In such 
circumstances, there is a transition from a "mono" language personality to a "multi" language personality. Education plays an important role in this transition: it is one of the most important factors influencing the formation of the language personality, its type and form, performing one of the long-term youth's mobility practices.

Cross-cultural aspects of interaction and language (communicative) personality are the subject of current research in sociolinguistics, pedagogy, sociology, culture sciences etc. Our work is based on the studies by Verhoeven and Vermeer (2002) of the communicative competence; on Boccio and Beaver (2016) idea about the association between multilingualism and psychopathic personality traits; on Dewale and Stavans (2014) research reflecting the peculiarities of Israeli multilinguals; by Chang, Kyungil, and Chung (2007) research on the relations between personality and language use; by Piatkowska (2012) ideas on the relationship of personality types and foreign language learners' perceptions of other cultures. As the core idea of the behavior we used Habermas (2000) approach to the explanation of human action and the origin of communicative action.

Cross-cultural communication deals with a particular type of person - language personality.

Language personality is a nationally specific communicant type that has a culturally caused worldview and value system, and is capable of cross-cultural transformation. Typologies of language personalities:

- In psycholinguistics: extrovert and introvert personality.

- In ethnolinguistic: the representative of basic and marginal cultures.

- In communication theory by language type: culture, elite, middle-literature, vernacular, folk-spoken, jargoning language personality.

Language personality includes all the communication codes. We offer to define the following levels in the development of communicative personality:

1) Denial of cross-cultural differences

2) Denial of another culture

3) Understatement, minimizing cultural differences

4) Cultural relativism

5) Adapting to other cultures

6) A higher level of cultural adaptation

Since we research language personality mainly through its communicative function, we consider "communicative personality" to be a synonym of a "language personality".

Research by Andreichik (2012) points out the need to create a "literacy package" designed to facilitate the adaptation of individuals and groups in society. We share this viewpoint, which in fact calls for an expansion of the interpretation of literacy beyond the linguistic competence of the individual.

Today, there is an increasing need to use technologies of "global literacy" ("cross-cultural literacy"), especially among young people. In UNESCO policy documents, such as Global education monitoring report (2016) pointed on the necessity of implementation of lifelong education as condition of sustainable development: "Learning, creating awareness and building competencies to take action can take place in communities and through education that is based in the interaction between people and their local environments. Indigenous knowledge and belief systems can inspire better stewardship of the planet. Lifelong learning can help people live more sustainably all their lives. A multistakeholder, collaborative approach should involve government, civil society and the private sector inside and outside schools to shape values and perspectives, and contribute to the development of competencies to reduce or stop unsustainable practices and to adapt to consequences such as climate change due to the overstepping of planetary boundaries by humankind". So, cross-cultural literacy was considered in the context of cross-cultural education (cross-cultural education) in the 80s. In the analysis of the principles and approaches implemented in these concepts, synonymy and the essential unity of the concepts of "global education" and "cross-cultural education" have been identified. Cultural pluralism, diversity and interdependence are recognized in the UNESCO principles of cross-cultural education.

From a global perspective, education includes at least the following components:

1) The ability to anticipate and understand the complexity of a multinational system;

2) Knowledge of the world culture and international events;

3) Understanding of the diversity and unity of human values and interests. 
Today there is a demand for the knowledge, skills and belief systems required to become responsible citizens. However, global education should not be limited to these principles. At a minimum, it is necessary to add the following components (Apanasiuk, 2002):

- The ability to realize the complexity of interdependence in terms of a certain system of concepts;

- The ability to do justice to the differences and similarities in different peoples' systems of values and interests.

\subsection{The Aim of This Research}

In our research we want to reveal the heuristic potential of the concept of "language personality" to analyze the effectiveness of cross-cultural communication at the micro level in local social group of participants of the international exchange program MASA-16 program at Ariel University. To achieve this goal, we conducted an empirical study to define the features of the current language personality of MASA-16 participants (MASA-ATZiL-Ariel: description of the program, 2017).

\subsection{The Main Hypothesis}

Our hypothesis is that transition from mono- to multi-language personality directly correlates with engagement in various types of social mobility.

\section{Data Analysis Section}

To receive the results we used several methods such as analysis and synthesis (while describing role of the language in modern life), the unity of the historical and logical (to determine the origin of "cultural literacy" and identifying indicators of successful cross-cultural communication), generalization and comparison (to identify the essence of the theoretical approaches to language personalities).

\subsection{Methodology of Obtaining Primary Sociological Information (Empirical Survey)}

We used a quantitative sociological survey, namely the case-study of the students participating in the MASA-16 Ariel program, with the help of a prepared list of questions. Additionally, all the respondents could add their comments to each question, which were analyzed after the survey. There were sixty participants, and fifty-two of them $(86 \%)$ were interviewed. All respondents were asked to complete the questionnaire anonymously. We controlled the following characteristics: age, sex, country of origin, major at Ariel University. The remaining participants who were not interviewed are matched in these features to the interviewed group. To control the quality of received results we used substantial and logical control of the received answers. As a result, the findings of this survey are representative, accurate and valid. Table 1 presented short description of the sample (those, who were interviewed).

Table 1. The description of the sample (\%)

\begin{tabular}{llr}
\hline 1. Gender & Men & 45 \\
& Women & 55 \\
\hline \multirow{3}{*}{ 2. Age } & Under 22 years & 25 \\
& $22-25$ years & 35 \\
& $26-30$ years & 40 \\
\hline \multirow{3}{*}{ 3. Education } & Finished BA degree & 60 \\
& Students obtaining BA-degree & 20 \\
& Finished school & 20 \\
\hline \multirow{3}{*}{ 4. Religion } & Christian & 35 \\
& Yehudi & 20 \\
& Do not follow any religion & 25 \\
5. Country of origin & Refused to answer & 20 \\
\hline & Russian Federation & 46 \\
& Ukraine & 42 \\
6. Ethnical identification & Other countries & 14 \\
\hline & Jewish & 55 \\
& Russians & 20 \\
& Ukrainians & 20 \\
\hline
\end{tabular}




\begin{tabular}{lll}
\hline \multirow{2}{*}{ 7. What courses are taking at Ariel University } & Management and international marketing & 48 \\
& Media and Communication & 42 \\
& Individual Research Program & 10 \\
\hline
\end{tabular}

To analyse the results of empirical survey we used program "PASW Statistics 18" and implemented such method as: categorical analysis (to identify different types of used languages, etc.), comparison method (to compare mother and daily used tongue), index method (to identify language skills and necessity of studying foreign languages), ranking method (to identify the place and the role of different factors, influencing on the appearance of communicative personality) etc.

\subsection{Key Findings}

Under the conditions of intensification of cross-cultural communications, only a new type of a language personality can be effectively integrated taking into account cultural peculiarities. Such type of language personality should have a specific competence of understanding different cultural codes and values. Language personality today acquires multicultural traits due to two main types of mobility: virtual mobility (social media language personality) and physical mobility. The participants in the Masa-Ariel project demonstrate the features of both types of mobility, with high demand for the study of international communication language (English) and local culture (Hebrew). Both demands indicate a willingness to remain highly mobile, which is typical for the younger generation in the twenty-first century. At the same time, there is a demand for knowledge about Jewish culture in general, which proves the formation of a multicultural language personality. To meet the need, we propose specialized communicative training as an addition to the existing ulpan, in order to facilitate the rapid acquisition of specific cultural codes while practicing the Hebrew language. In addition, our findings can form the basis for $t$ special PR campaigns, promotions and other events to promote specific programs and enhance their appeal in their target audiences.

\section{Technologization of Individuals and Group Training in Cross-Cultural Communications in the Context of the Dictionary of Cultural Literacy by E. Hirsch}

We rely on such structural elements of communicative competence as communicative competences, communicative skills, and communicative knowledge. Communicative knowledge includes understanding 1) the nature, types, patterns of communication; 2) communication methods and techniques, their capabilities and limitations; 3) the most effective forms and methods of communication for various individuals, groups and different situations; 4) the extent of communicative skills of individuals and groups; 5) methods and techniques of communication for which particular individuals (groups) are ready or not ready (Zinchenko, 2010). Communicative ability is usually seen as a natural endowment on the one hand, and on the other - as a communicative performance that manifests itself in the ability to perform communicative tasks of different complexity in specific historical multicultural situations (Zinchenko, 2010).

The notion of cultural literacy is becoming extremely relevant today in the scientific educational environment. Many scientists, pedagogues, and public figures talk about low level of general culture of their peers, trying to find solutions to this problem (Vorontsov, 2009).

The theory of American culture scientist E. Hirsch, which he called "cultural literacy," is devoted to the problem of cultural literacy development (Hirsch, 1988). Hirsch defines the term "cultural literacy" as follows: "the network of information that all competent readers possess. It is the background information, stored in their minds, that enables them to take up a newspaper and read it with an adequate level of comprehension, getting the point, grasping the implications, relating what they read to the unstated context which alone gives meaning to what they read" (p. 2). Cultural literacy focuses on the cultural information included in a nation's basic cultural foundation (mainstream culture), designated in the forms of the national literary language. This information is usually quite superficial and, as noted by G. G. Slyshkin, roughly in line with what in colloquial Russian language is called "banal erudition" (Slyshkin, 2000).

The existence of a single literary language as a means of communication requires a homogeneous form. Cultural uniformity in the presentation of E. Hirsch is limited to "citizenship," resulting in the following texts: the oath in the name of God, freedom of religion, respect for the anthem and the flag, and the facts of world history, geography, modern science, and politics (Kondratiev, 2017). Hirsch insists on the necessity of the dictionary that selects and interprets the names, phrases, events and other units known to people. Hirsh admits that only a small share of "educated Americans" know the content of each dictionary entry, while most of them are familiar with a large part of the information given in the dictionary, even if they are unable to give a precise definition of each 
word or phrase. We can conclude that the Dictionary of Cultural Literacy according to Hirsh demonstrates an extremely simplified domestic view of various aspects of culture, history, science, contemporary reality; clearly, there are stereotypes of mass consciousness. According to Hirsch, successful language knowledge requires a good awareness of the various cultural symbols of the target national culture. This kind of knowledge encompasses language values, communication peculiarities, text meaning and discourse specificity of a particular linguacultural community. For successful communication with other cultures, each person must possess the necessary minimal cultural knowledge of his partners in communication. In cross-cultural communications such competencies as linguistic, cultural and communicative are connected. Depending on the importance and role of this or that competence in specific situations of communication, Hirsch identifies the following levels of cross-cultural competence: necessary for survival; sufficient for entry into the foreign culture; providing a full existence in a new culture - its "interiorisation"; allowing to fully implement the identity of a language personality (Hirsch, Kett, \& Trefil, 2003).

Just as a single person cannot normally exist in isolation from other people, so no culture is able to fully function in isolation from the cultural achievements of other nations. In the course of their vital functions, they have to constantly refer to the past, or to the experience of other cultures. Today there are almost no cultures that are completely isolated from other cultural communities, except for small native tribes in the most secluded corners of the planet. Today, it is natural that nations are open to perceive the cultural experience of others and at the same time are ready to share with the other peoples the products of their own culture. This appeal to the cultures of other nations is known as "cultural interaction" or "cross-cultural communication". Typically, these concepts are treated as synonyms, although they have some distinctions.

In our view, the indicators of successful cross-cultural communication are as follows:

- Availability of communicative intentions, desire to send a message;

- focus on cooperation;

- The ability to distinguish between collective and individual in the communicative behavior;

- Ability to overcome stereotypes;

- Possession of a set of communication tools and their correct choice depending on the situation of communication (tone, style, speech genres);

- Adherence to the logic of discourse;

- Desire for communication symmetry;

- Adherence to etiquette rules.

Language of communication knowledge based on non-verbal, non-verbal and culturally conditioned paraverbal features must be added to this list.

\section{Language Personality in Expert Evaluation of the Participants of the MASA-16 Ariel Program}

\subsection{The Concept of Linguacultural Literacy}

Modern society, especially the younger generation, sometimes have a low level of knowledge of linguacultural units, which seem to be well known to all native speakers. To overcome this, Ansimova (2014) offers the concept of linguacultural literacy, which can serve as a basis for creating a dictionary or lexicographical interpretation unit that contains minimal background information and is focused on communication.

Apanasyuk indicates that students' cross-cultural literacy, or the understanding of the culture of another nation is the unity of knowledge about their own and other cultures, their understanding and positive attitude towards them. Development of students' cross-cultural literacy can be successful when the following pedagogical conditions obtain (Apanasiuk, 2002):

- The content of students' development of cross-cultural literacy is defined;

- Students' mastery of the different types of scientific knowledge is combined with the development of their capacity for pedagogical reflection, which brings them into the sphere of philosophical understanding of cultural values both of their own and of other people, and for theoretical pedagogical reflection, which regulates and directs students' engagement in the culture of another nation;

- Reflective work, serving as a prerequisite of equality understanding of different cultures, recognition of the value of diverse cultural worlds, gives students the opportunity to make a choice of cultural values, to discover the informative and valuable contents of their own and other cultures; 
- The development of students' positive attitude to their native culture and another culture. Their tolerance is enhanced by such an organization of the learning process, in which the students analyze reflective relations of the interacting individuals, reproducing their subjectivity, and the analysis is conducted in terms of human values, unanimously adopted by different cultures;

- The process of mastering students' scientific knowledge of various types, the implementation in the educational process of creative, individual, group assignments, the solution of pedagogical tasks, organization of discussions combined with the orientation on familiarizing students with the values and culture of their and another nation.

\subsection{Indicators of Empirical Survey}

In our empirical study, we sought to determine the extent to which the participants in the MASA-16 program at Ariel University possess the elements that form a language personality. To do this, we collected the following data:

- $\quad$ Native language;

- Language of the modern communication;

- Knowledge of different languages;

- Desire to improve knowledge of different languages;

- Motivations for improving knowledge of different languages;

- Needs of knowing other languages;

- Reasons of needs to know other languages;

- Sources of information about the world around us;

- $\quad$ Purposes of Internet use;

- $\quad$ Frequency of Internet use;

- Duration of Internet use;

- Variety of profiles in social media.

We correlated these indicators with values and mobility. The peculiarities of language personality were calculated at the group level.

\subsection{Results of the Authors Empirical Survey}

The results showed that for more than $90 \%$ of the respondents, Russian language was both the native language and the language of daily use (see Figure 1). In these questions, MASA-participants could choose more than one answer. For half of the participants from Ukraine, their native language is Ukrainian, but this is not the language of daily use. At least one quarter of the participants identify themselves as bilingual.

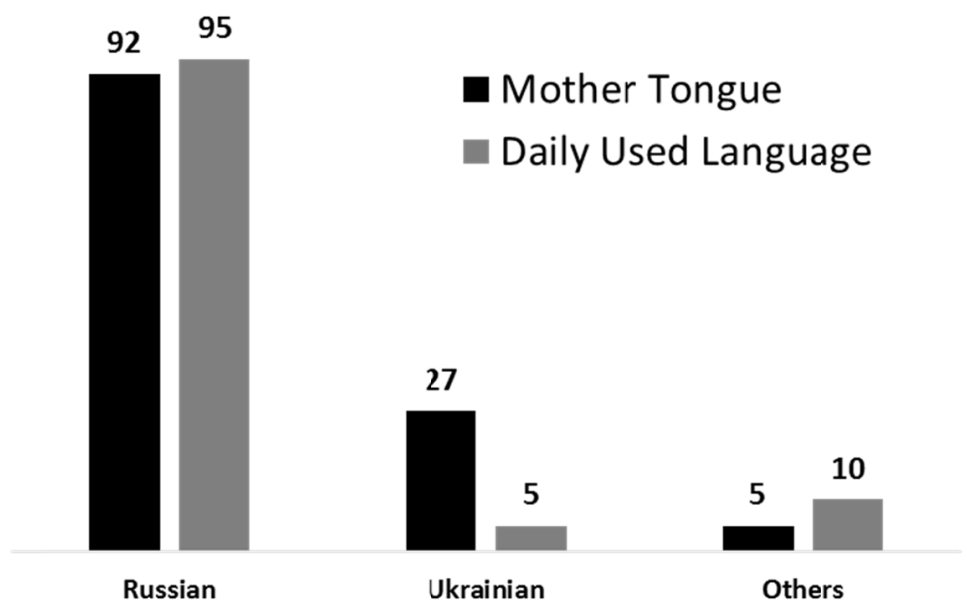

Figure 1. Mother tongue and daily used language (\%; several answers) 
One of the features of the participants is knowing several languages (see table 2). Half of the participants know English on the level that is sufficient to communicate with others, and about $15 \%$ also mentioned other languages that they can use in daily communication (e.g., German, French, Italian,). Hebrew is still difficult to use for the majority and Arabic is totally "terra incognita" for all participants. Such a situation shows that the language personality of MASA-participants has international features (they know English), but they might have problems understanding the culture and worldview of local inhabitants.

Table 2. Language skills (\%)

\begin{tabular}{llllll}
\hline \multirow{2}{*}{$*$} & Language skills & \multicolumn{4}{c}{ Languages } \\
\cline { 2 - 6 } & & Hebrew & English & Russian & Arabic \\
\cline { 2 - 6 } & I don't know at all & 0 & 2.6 & 0 & 97.5 \\
2 & I know only some words and expressions & 65 & 20.5 & 0 & 2.5 \\
3 & I can use basic language structures & 30 & 10.3 & 0 & 0 \\
4 & I understand, but it is difficult to speak and write fluently & 5 & 38.5 & 2.5 & 0 \\
5 & I speak and write fluently & 0 & 28.2 & 97.5 & 0 \\
& Average index (according to all positions): & 2.4 & 3.69 & 4.97 & 1.03 \\
\hline
\end{tabular}

The necessity to know the official state language of the country of destination is understood by all the MASA-participants (see table 3), which is an important aspect of life in a new country. The need to know Hebrew, which is the official language of Israel, is acceptable to the respondents. However, in some cases, such as communication in public places (transportation, cafes), while communicating with people in the street English can be a competitor. More these, English is more appreciable while communicating with the representatives of different nationalities. Russian language is important for communications between MASA participants and teachers (indexes higher than 4 points), in other cases, Russian is not useful. An exception is while communicating with people in the street. From the respondents' point of view, Russian is more important even than Arabic, which received indexes of less than 2 points. An exception is for communication with other nationalities (2.15) and for better understanding the culture of Israel.

Table 3. The need for language knowledge in the country of stay (\%) (indexes. 5 - very important, 1 - absolutely unimportant)

\begin{tabular}{|c|c|c|c|c|c|c|}
\hline \# & Use of language & $\begin{array}{c}\text { Knowledge of the state } \\
\text { language where you arrived }\end{array}$ & $\begin{array}{c}\text { Hebrew in } \\
\text { Israel }\end{array}$ & $\begin{array}{c}\text { English in } \\
\text { Israel }\end{array}$ & $\begin{array}{c}\text { Russian in } \\
\text { Israel }\end{array}$ & $\begin{array}{c}\text { Arabic in } \\
\text { Israel }\end{array}$ \\
\hline & While applying for a job & 4.57 & 4.55 & 3.9 & 2.75 & 1.85 \\
\hline & $\begin{array}{l}\text { While solving problems at public } \\
\text { institutions }\end{array}$ & 4.32 & 4.35 & 3.42 & 2.45 & 1.65 \\
\hline & $\begin{array}{l}\text { While getting medical care } \\
\text { (communication with a doctor) }\end{array}$ & 4.2 & 4.4 & 3.67 & 2.58 & 1.48 \\
\hline & In public places (transport, cafe) & 3.75 & 3.88 & 3.65 & 2.75 & 1.83 \\
\hline & $\begin{array}{l}\text { While communication in Israeli } \\
\text { universities in general }\end{array}$ & 3.88 & 4.22 & 3.47 & 2.65 & 1.6 \\
\hline & $\begin{array}{l}\text { While communicating with people in the } \\
\text { street }\end{array}$ & 3.7 & 3.83 & 3.75 & 3.13 & 1.88 \\
\hline & $\begin{array}{l}\text { For understanding the culture of the } \\
\text { country }\end{array}$ & 3.65 & 3.88 & 2.83 & 2.47 & 2.13 \\
\hline & $\begin{array}{l}\text { While communicating with the } \\
\text { representatives of different nationalities }\end{array}$ & 3.42 & 3.58 & 3.72 & 2.58 & 2.15 \\
\hline & While visiting theatres, museums etc. & 3.4 & 3.7 & 3.28 & 2.6 & 1.58 \\
\hline & $\begin{array}{l}\text { While communication between the } \\
\text { MASA participants and the teachers }\end{array}$ & - & 2.65 & 2.78 & 4.03 & 1.4 \\
\hline & $\begin{array}{l}\text { While communication between the } \\
\text { MASA participants }\end{array}$ & - & 2.13 & 2.1 & 4.45 & 1.3 \\
\hline & $\begin{array}{l}\text { Average index } \\
\text { (according to all positions): }\end{array}$ & 3.6 & 3.74 & 3.32 & 2.95 & 1.7 \\
\hline
\end{tabular}


Almost all respondents expressed the need to improve their Hebrew (see Figure 2). Four-fifths would like to improve their English and only 5\% mentioned Arabic. Respondents commented that they don't see the need to study Arabic, which is the language of a minority, because it won't help them to meet practical goals (job, study at university etc.). Of course, participants don't think that Arabic can help them better understand Israeli culture.

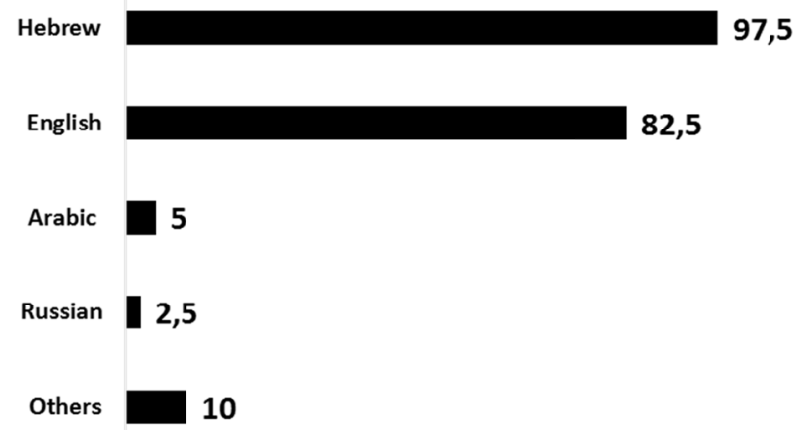

Figure 2. Which language do the respondents want to improve? (\%; several answers)

Our results show that most valued feature of language personality is its Internet orientation. We can even say that "social media language personality" is common to most of the participants (see fig 3). Respondents' worldview is formed by social networks, chats $(87.5 \%)$ and websites $(60 \%)$. Friends, who are socialization agents, share first place with social media. Personal experience as a means of obtaining information, is typically less than a half of the responds. Media such as television, telephone and radio, which were traditional in the twentieth century, are no longer in favor.

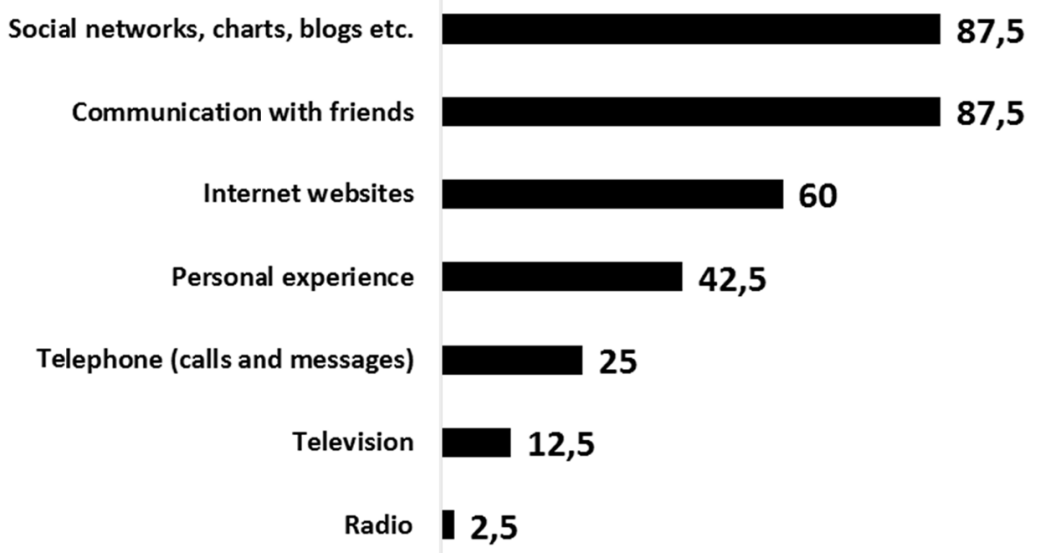

Figure 3. The ways of receiving information (\%; several answers)

Our respondents either constantly use Internet (52.5\%) or check it several times a day (45\%). Half of the participants use the Internet more than one hour a day, and only $12.5 \%$ used it for a limited time, only when it is necessary. That explains the important role of this type of communication (see table 4-5). 
Table 4. Frequency of the Internet use (\%)

\begin{tabular}{llc}
\hline$\#$ & Duration & $\%$ \\
\hline 1 & Constantly & 52.5 \\
2 & Several times a day & 45 \\
3 & A few times in 2-3 days & 2.5 \\
\hline
\end{tabular}

Table 5. Duration of the Internet use (\%)

\begin{tabular}{clc}
\hline$\#$ & Duration & $\%$ \\
\hline 1 & Limited time period, only when it is necessary & 12.5 \\
2 & Up to a half of an hour & 10 \\
3 & A couple of hours & 17.5 \\
4 & Stay online all the time, use as soon as ever I can & 30 \\
5 & Difficult to say & 30 \\
\hline
\end{tabular}

Communication is the main reason for the constant use of (total 242.5\%): social media, communication in different messengers, e-mail, and skype (see Figure 4). The second group of reasons is information: searching for necessary information, getting the news, cultural development, downloading necessary information (total 232.5\%). The third group of reasons is leisure and shopping: watching movies, YouTube, online shopping, Internet-TV, online games (total $172.5 \%$ ).

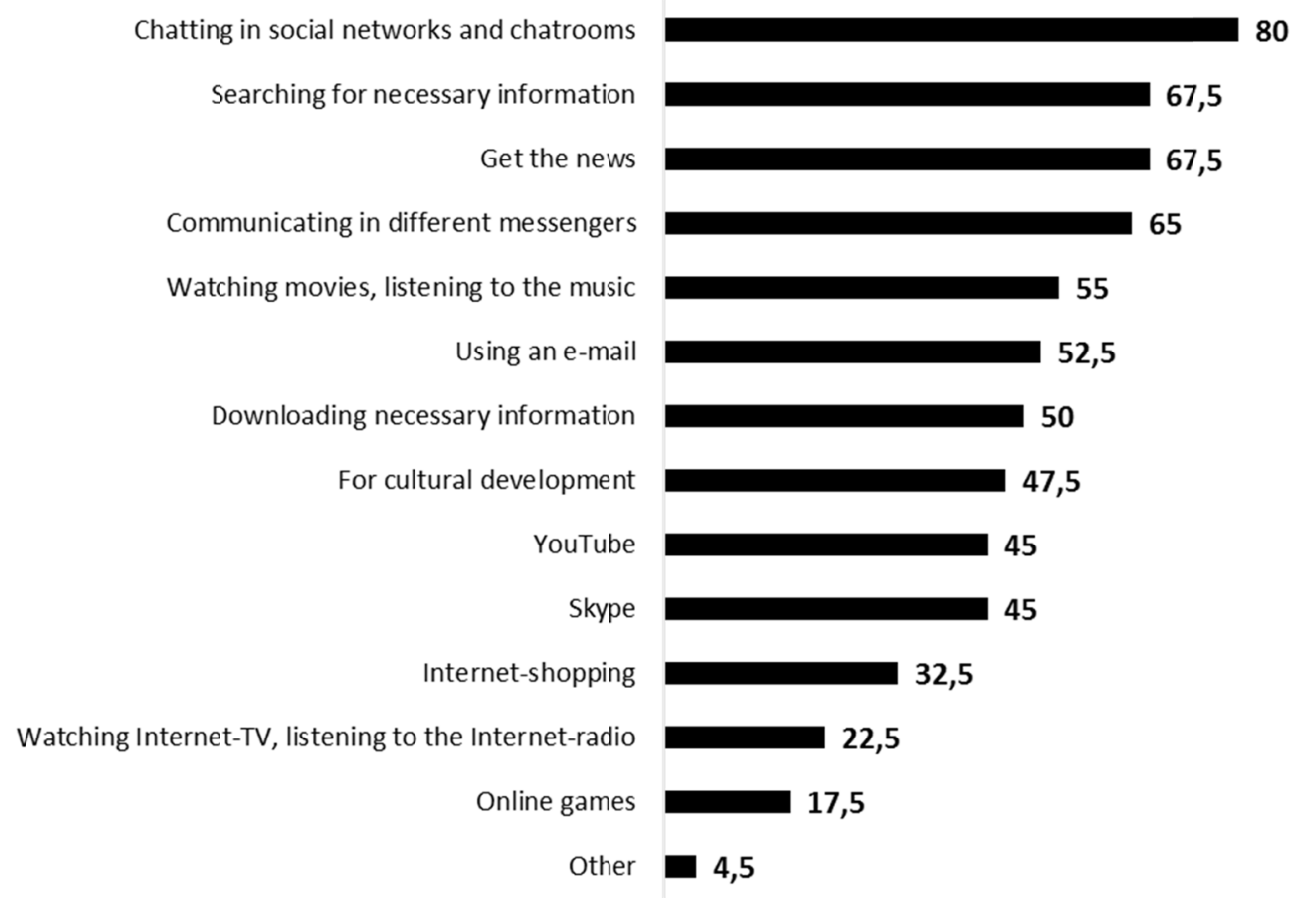

Figure 4. Why Internet is used (\%; several answers)

Among social media, which is the main reason for using the Internet and obtaining information, VK and Facebook are the most popular platforms (see Figure 5). 


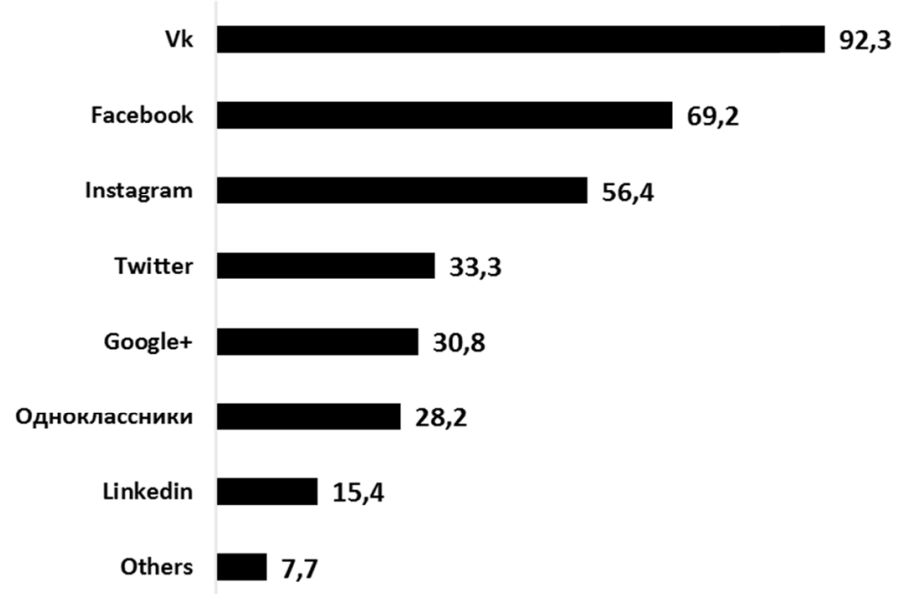

Figure 5. Using social networks (\%; several answers)

Ninety-five percent of respondents indicated that they have experience in travelling abroad, but in most cases, their purpose was tourism (86.8\%), and only 10 percent travelled for the purpose of studying (see Figure 6).

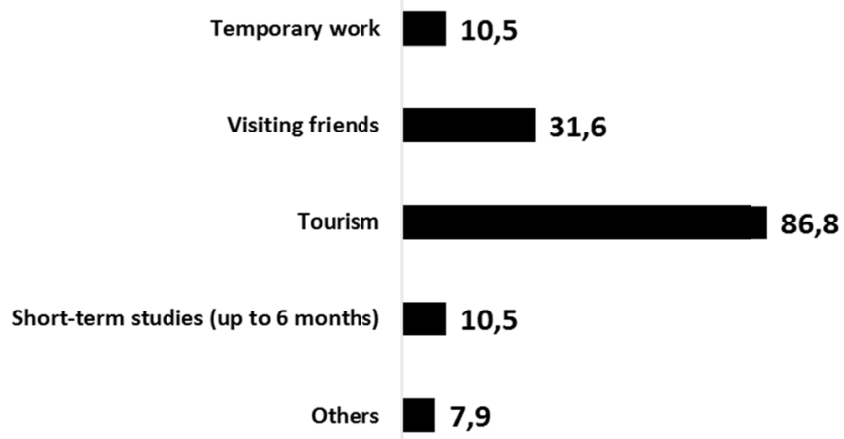

Figure 6. The Purpose of overseas travel (\%)

It should be noted that almost all the respondents who stated that they had studied abroad are participants of the second stage of the MASA program, so we can say that for the vast majority of respondents MASA was their first experience of studying abroad. In fact, their mobility was limited to a virtual journey through the Internet and tourism. Continuous learning experience in another country, as well as cultural knowledge, requires special adaptation technologies for such a group, which can be communicative training.

\section{Communicative Training as a Technology of Increasing the Efficiency of Cross-Cultural Communication}

The importance of language learning is an undeniable reality, and the participants of the MASA-16 program also share this opinion. It is obvious that with increasing mobility, the need for knowledge of foreign languages, including the knowledge of other cultures, also increases.

In our opinion, language culture reflects the ability of its carrier to use language forms, norms, constructions in accordance with the values and cultural norms adopted in a particular society. Therefore, it is logical, in our opinion, to include cultural literacy in the so-called "literacy package". Thus, T. Beleniuk rightly believes that the concept of "cultural literacy" can be considered as a means of overcoming the cultural barrier in the context of intercultural communication. Accordingly, cultural literacy presupposes the formation and development of certain qualities and abilities of the linguistic personality that go beyond the scope of only linguistic competence (Beleniuk, 2012). 
Language personality is a specific type of national communicant, which has a culturally caused worldview and value system and is capable of cross-cultural transformation; these communicative skills can and should be trained and developed. It is crucial to show young people how these skills can be implemented in practice, help them learn the culture of a foreign country through the perspective of its language. In order to become a language personality, it is not sufficient to travel and communicate with native speakers - although, it is the most pleasant part of the learning process. It will definitely give a person a general impression of what a culture is, but it is incapable of making one share the values and orientations of this culture, and become a part of it. For this, only time and specific techniques are helpful. Let us put time aside, as it is the most precious human resource, and try to think of means that require fewer efforts. Communicative training is certainly one of the most effective focused technologies for developing language personality.

The theoretical and methodological foundation for organizing and conducting communicative training, focused on effective cross-cultural communication, can be the theory of high and low-context cultures developed by Hall (1977) and the theory of cultural literacy developed by Hirsch. High-context cultures distinguish unexpressed, hidden manner of speech, ambiguous and numerous pauses; leading role of nonverbal communication; extra information as for communication it is enough to have primitive background knowledge; no public showing of dissatisfaction with any conditions and results of communication. Low-context cultures are characterized by the following features: direct and expressive manner of speech; a small proportion of non-verbal forms of communication; a clear evaluation of all the discussed topics; rating understatement as a weak awareness of an interlocutor; open expression of discontent. In specific communicative situations, Hirsch identifies such levels of cross-cultural competence that become the foundation for communicative training, and necessary for survival; sufficient for entry into the foreign culture; they provide full existence in a new culture - its "assimilation," allowing one to become a language personality (Sidorenko, 2008).

Communicative training is designed to prepare participants for informational exchanges and consideration of the layered structure of communicative knowledge. The content of communicative training should take into account cross-cultural features of cross-cultural such as "the difference between man and machine, gender, age, cultural, educational, ideological, social status, personal, family, dialectical language, situational characteristics speakers of languages and cultures" (Leontiev, 2006). Researchers outline the following structural features in which cultures differ from one another: "1) national character, identity baseline; 2) perception of the world; 3) the experience of time; 4) the experience of space; 5) thinking; 6) language; 7) non-verbal means of communication; 8) the value orientation; 9) patterns of behavior, customs, norms, roles; 10) social groups and relations" (Hirsch, 1988).

A manifestation of inefficient cross-cultural communication is a cultural shock that is often provoked by cultural distance, and more precisely, its subjective perception. Cultural shock is the stressful impact on a person of a new culture, a short-term sense of disorientation and discomfort experienced by an individual in a new culture and accompanied by psychological illness. Oberg introduced the term in 1960 to describe the mechanism of culture shock. He coined the term "U-shaped curve." U: Good, bad, very bad, better, good. The stages of cultural shock are:

1) Enthusiasm;

2) The negative impact of the environment;

3) Critical point;

4) Optimistic mood;

5) Adapting to a foreign culture.

Reverse (reverse) cultural shock can be described as a "W" - steps to the rehabilitation of their own culture (L. Khyzhniak \& K. Khyzhniak, 2014).

Therefore, the objectives of communicative training must inevitably include exercises (technologies) for reducing the cultural distance between speakers from different cultures and for mitigating culture shock. One of these means of communicative training is development of individuals' linguistic competence, which promotes understanding of different cultural codes.

Such culture shock causes communicative drama. With the help of communicative training, it can be possible to overcome communicative dramas, which in practice are divided into five dramas: the drama of listening (the ability to listen to another person), the drama of understanding (the ability to understand another person), the drama of action (the ability to act according to one's understanding), the drama of self-expression (the ability to express one's thoughts and feelings), the drama of emotion (the ability to regulate emotional stress in correlation 
with a representative of another culture) (Zinchenko, 2010). The list of the given dramas, in our opinion, is not exhaustive and may be supplemented with dramas generated by a crisis of consciousness, which is inherent instability and inconsistency. For example, there are the drama of inertia (unwillingness to overcome difficulties in the process of communication, such as lack of motivation to learn the language, history and culture of the environment in which the individual intends to reside permanently or temporarily), the drama of dogmatism (the lack of desire to get rid of old ideas, views).

In practice, the following types of communicative trainings are used: 1) professional communicative training designed for professionals, which is based on communication with people (managers, salespeople, teachers, service workers and others). 2) Communicative training serves to build relationships with the opposite sex. 3) Communicative training for specific age groups, because communication difficulties are often age related (young, middle-aged, the elderly). 4) Communicative training for practicing behavior in extreme or crisis situations (hostage seizure, pressure from colleagues, classmates, relatives, bosses pressure and so on.). 5) Basic communicative training for all individuals who have problems communicating. This is the basis of all communicative training, regardless of the specific type (Palagar, 2013).

In communicative training, language is essential. Language is the leading means of communication. In the communicative process, language is recognized worldwide as a thinking tool that allows images to provide certain values and signs and transfer of experience and knowledge. Knowing the host country's language helps to avoid cross-cultural misunderstandings that arise when working through an interpreter. Language skills greatly accelerate and facilitate the process of establishing local acquaintances and professional contacts.

\section{Conclusions}

Today, understanding literacy in its broader social context has become widespread. Cross-cultural communications entail a number of risks and barriers. Under the condition of globalization and the intensification of social interactions, building effective cross-cultural communications is becoming relevant. Building effective cross-cultural communications requires a comprehensive multi-layered approach, taking into account the specificity of different forms of cross-cultural communications.

According to the results of our study, we believe it is possible to adopt a new perspective on the heuristic possibilities of the concept of language personality to ensure the effectiveness of cross-cultural communications.

We offer to define a language personality as a nationally specific communicant type that has culturally caused worldview and value system and are capable of cross-cultural transformation.

Following Hirsch, we believe that language personality cannot be viewed from the perspective of evaluating language skills. This applies above all to the understanding of culture, cultural codes, verbal, non-verbal communication and paraverbal development of value measurement and understanding, and in some cases, adoption of behavioral patterns. Today, conditions are created for the mass formation of multicultural language personalities that have come to replace the mono-cultural language personality, limited by the specificity of its culture.

Educational institutions play a decisive role in developing a multicultural language personality.

We agree with Apanasiuk (2002) who indicates that students' cross-cultural literacy, or the understanding of the culture of another people, is the unity of knowledge about their own and other cultures, their understanding and positive attitude towards them. Universities throughout the centuries have been the centers of science, culture and education. Today, in view of growing academic mobility of teachers, students,) knowledge and competences, the need for learning foreign languages has increased, and specifically the need to acquire an education. At the same time, a new type of highly mobile individual is forming, who, in the words of Bauman, "hovers" in everyday life. In such circumstances, there is a growing need in the short term, not merely for learning a language for communication, but also for understanding the culture of the host country.

In terms of our empirical research of the participants of the Masa program at Ariel University, we identified the following: little knowledge of English is sufficient for everyday use; high demand for the study as an international language of communication (English), and the local language (Hebrew); a desire to know the culture of the host country, which in this case is Israel; appreciation of the importance of knowing the local language of communication for the development of a new culture, etc. We also found the key features of this group, namely the formation of the social network language personality, as most of the participants use the Internet in general and social media in particular as the main channel of communication and knowledge of the world and interactions with others. Thus, our hypothesis was partially confirmed: Social mobility directly correlates with the need and knowledge of foreign languages, but there was no statistically significant 
association between mobility and the transition from a mono- to a multi-language personality. The researched group is an example of how specific technologies can be developed to improve cross-cultural communications. In view of the findings, we propose communicative training as one of the technologies to achieve this goal.

Communicative training constructs a certain model of communication: a schematized, simplified display of a real communicative process. It becomes a necessary tool to study and control the communicative process. Communicative training becomes a manipulative technology if its members are not aware of its explicit and latent functions. The value context of a communicative training promotes multiculturalism, by providing the logical justifications for the transition from monoculture to multicultural person. In addition, multiculturalism is manifested not only in external communications, but also in internal communication.

We offer using communicative training as a technology for developing a language personality. We argue that such training should be specialized and aimed at specific target groups. We offer the following key principles:

- take into account the specifics of the countries of origin of the similar MASA programs participants. For example, the states focused on democratization or the construction of the authoritarian regime;

- take into account the specifics of the countries of origin. For example, what religion is dominant, what type of culture (individualistic or collectivist-oriented), etc.;

- take into account the cultural distance, including what values, norms participants can immediately be accepted and eventually followed, and that practically do not change in their communications.

Such training must set the goal of the "language" the alignment of the participants when they do not just learn the language (ulpan is used for this), but learn to understand and accept a new culture in the communication with new thinking. From our point of view, such training should become a sort of a "bridge" between adaptation to Israeli culture and the culture of participants' country of origin. Namely, training involves the development of new skills in a short period of time, so it can perform a logical addition to the training calendar.

We know that the history of communication development is related to the development of data transmission, and has undergone three communicative revolutions: the invention of writing; the invention of the printing press (the beginning of "the era of Gutenberg"); the development of electronic media. In the future, it is reasonable to study the role of training in improving the efficiency of communication in the virtual world, the expansion of which humanity is now experiencing.

\section{Acknowledgments}

Generous support was provided by the grant of the Project "MASA-ATZiL-Ariel (2016-2017)" (Israel) under supervising of Vladimir Yunaev.

\section{References}

Andreichik, N. I. (2012). Formation of lingual cultural competence as a factor in mastering the language culture. Universal and national in culture (pp. 375-382) [in Russian].

Ansimova, O. K. (2014). The conception of lingual cultural literacy: relevance and perspectives. Philology and literature studies, 7. Retrieved from http://philology.snauka.ru/2014/07/844

Apanasiuk, L. A. (2002). The forming of students' cross-cultural literacy in the process of studying at pedagogic university. Samara: Samara State University, 218. Retrieved from http://www.dissercat.com/content/formirovanie-kross-kulturnoi-gramotnosti-studentov-v-protsesse-obuchen iya-v-pedagogicheskom-\#ixzz4OVo9N3qi

Beleniuk, T. N. (2012). Overcoming a culture barrier in the process of learning a foreign language. Philological sciences. The issues of theory and practice, 2, 33-35

Boccio, C. M., \& Beaver, K. M. (2016) The Association Between Multilingualism and Psychopathic Personality Traits. Journal of Criminal Justice, 47(1), 151-158. https://doi.org/10.1016/j.jcrimjus.2016.09.003

Chang H. L., Kyungil, K., Young, S. S., \& Chung, C. K. (2007). The relations between personality and language use. The Journal of General Psychology, 134(4), 405-413. http://dx.doi.org/10.3200/GENP.134.4.405-414

Dewaele, J., \& Stavans, A. (2014). The effect of immigration, acculturation and multicompetence on personality profiles of Israeli multilinguals. The International Journal of Bilingualism, 18(3), 203-221. https://doi.org/10.1177/1367006912439941

Global education monitoring report. (2016). Education for people and planet: Creating sustainable features for all. Retrieved from http://unesdoc.unesco.org/images/0024/002457/245752e.pdf 
Habermas, J. (2000). Moral consciousness and communicative action. Saint-Petersburg: Nauka [in Russian].

Hall, E. T. (1977). Beyond Culture. Anchor Books, New York.

Hirsch E. D., Jr., Kett J. F., \& Trefil J. (2003). The new dictionary of cultural literacy. The Booklist, 99(18), 647.

Hirsch, E. D. J. (1988). Cultural literacy: What every American needs to know. Vintage Books, 272.

Khyzhniak, L., \& Khyzhniak, K. (2014). Communicative training as a technology of improving the efficiency of cross-cultural communication. Social Technologies. Relevant Problems of Theory and Practice, 62, 173-179 [in Ukrainian]. Retrieved from http://www.irbis-nbuv.gov.ua/cgi-bin/irbis_nbuv/cgiirbis_64.exe?I21DBN= LINK\&P21DBN $=U J R N \& Z 21 \mathrm{ID}=\& \mathrm{~S} 21 \mathrm{REF}=10 \& S 21 \mathrm{CNR}=20 \& \mathrm{~S} 21 \mathrm{STN}=1 \& \mathrm{~S} 21 \mathrm{FMT}=\overline{\mathrm{ASP}} \_$meta\&C $21 \mathrm{C}$ $\mathrm{OM}=\mathrm{S} \& 2 \_\mathrm{S} 21 \mathrm{P} 03=\mathrm{FILA}=\& 2 \_\mathrm{S} 21 \mathrm{STR}=$ stapttp_2014_62_23

Kondratiev, A. (2017). Main theories of intercultural communication [Weblog, in Russian]. Retrieved from $\mathrm{http}$ ://www.grandars.ru/college/sociologiya/teorii-mezhkulturnoy-kommunikacii.html

Leontiev, A. (2006). Personality, culture, language. Journal of Russian \& East European Psychology, 44(3), 47-56. https://doi.org/10.2753/RPO10610405440304

MASA-ATZiL-Ariel: description of the program. (2017). Retrieved from http://www.ariel.ac.il/masa/ru

Palagar, J. (2013). Socio-affective borders in figurative language production. International Journal of Arts \& Sciences, 6(3), 335-345. Retrieved from http://www.universitypublications.net/ijas/0603/pdf/HVD176.pdf

Piatkowska, K. (2012). The relationship of personality types and foreign language learners' perceptions of other cultures. International Journal of Arts \& Sciences, 5(7), 375-388.

Sense of Belonging - Guidelines for Values for the Humanistic and International Dimension of Education. (1983). Retrieved from http://unesdoc.unesco.org/images/0009/000986/098671e.pdf

Sidorenko, E. (2008). The communicative competence training in a business interaction. Saint-Petersburg, Rech [in Russian].

Slyshkin, G. (2000). Lingual cultural concepts of precedent texts. Moscow. Academia, 142 [In Russian].

Veltkamp, G. M., Recio, G., Jacobs, A. M., \& Conrad, M. (2013). Is personality modulated by language? The International Journal of Bilingualism, 17(4), 496-504. https://doi.org/10.1177/1367006912438894

Verhoeven, L., \& Vermeer, A. (2002). Communicative competence and personality dimensions in first and second language learners. Applied Psycholinguistics, 23(3), 361-374. https://doi.org/10.1017/S014271640200303X

Vorontsov, R. I. (2009) Cultural literacy: American version. Herzen University Newsletter, 3, 51-57.

Vorozhbitova, A., \& Issina, G. (2014). Professional Linguistic Personality as Subject of Discursive Processes: Conception of Linguistic Rhetorical Culturological. Education. European Journal of Social and Human Science, 1(1), 44-55. Retrieved from http://ejshs.net/journals_n/1396777591.pdf

Zinchenko, V., Zusman, V., Kirnoze, Z., \& Ryabov, G. (2010). Intercultural communication dictionary. Notions and personalities. Moscow. Flinta, Nauka, 136 [in Russian].

\section{Note}

Note 1. MASA-16 participants at Ariel University are the group of youth from the post-Soviet countries that attend Ariel University for a short period, to study different subjects and travel in Israel in order to become acquainted with the country's culture and history. They are young persons from 18 to 30 years old, who came to study several courses on "Management and international marketing", "Media and Communication" or "Individual Research Program" from Post-Soviet countries. Each of the participants has different national, religious or language identity (but each of them can speak Russian language to study the Program).

\section{Copyrights}

Copyright for this article is retained by the author(s), with first publication rights granted to the journal.

This is an open-access article distributed under the terms and conditions of the Creative Commons Attribution license (http://creativecommons.org/licenses/by/4.0/). 